\title{
TEORIAS ECONÔMICA, JURÍDICA E SOCIAL DA EMPRESA
}

\author{
Jason Albergaria Neto ${ }^{1}$ \\ Rafael Braga de Moura ${ }^{2}$
}

\section{Resumo}

O desenvolvimento da sociedade empresária é um tema bastante discutido na doutrina e jurisprudência, tendo em vista que para se chegar ao seu desenvolvimento se faz necessário passarmos pelo conceito de empresa. Assim, nosso objetivo não será o de concluir o que seria empresa, tendo em vista que a nosso ver não teria como, se ter uma definição única e estática do que é empresa, porém, buscaremos demonstrar quais são as teorias escritas desde meados do século XVIII até atualmente no século XXI, onde se buscou chegar - e foi o que chegou mais perto - ao que seria o conceito de empresa. Após utilizar-se de métodos bibliográficos de diversas épocas, ou seja, desde os primeiros estudos sobre direito comercial, até os atuais de direito empresarial, chegou-se ao resultado de que o conceito de empresa não pode ser tido como estático, deve sempre estar em modificação, ora utilizando os conceitos e justificativas, sociais, econômicos e jurídicos. Conclui-se então, em considerações finais que tanto o conceito econômico, como o jurídico e o social podem ser aplicado para conceituar a empresa, dependendo do momento e do resultado esperado, não existindo um conceito único para empresa.

Palavras-chave: Direito Comercial. Direito Empresarial. Conceito de Empresa. Teorias da Empresa. Atos de Comercio.

\section{INTRODUÇÃO}

O conceito jurídico da empresa, como descreveu Georges Ripert, decorre de uma série infindável de fatores, que vão desde a aplicação do vocábulo a situações extremamente diferentes até o uso indiscriminado da palavra pelo legislador, estrangeiro e brasileiro. (RIPERT, 2002)

Também descreve Waldírio Bulgarelli que o conceito jurídico da empresa é o mesmo no conceito sociólogo, religioso, econômico ou político, formulados cada um na sua linguagem da ciência. (BULGARELLI, 1995)

Existem diversos autores que abordaram sobre o tema, como Cesare Vivante, Alfredo Rocco, José Xavier Carvalho Mendonça, Gladston Mamede, Rubens Requião, Ricardo Negrão, dentre muitos outros autores.

\footnotetext{
${ }^{1}$ Doutor em direito comercial pela UFMG, Professor Titular de Processo Civil na Faculdade Milton Campos, Procurador do Estado de Minas Gerais. E-mail: jasonneto@jasonalbergaria.com.br

${ }^{2}$ Mestrando em direito empresarial pela Faculdade de Direito Milton Campos; Filiado à Faculdade de Direito Milton Campos. Email: rafael.braga@bbrs.com.br
} 
Assim, para melhor elucidar o trabalho, buscará analisar os conceitos nas três áreas, tanto econômica, como jurídica e por sim a social.

Tem-se que o problema teórico do tema é a falta de conceito aceitável para as empresas, onde as três áreas utilizam um conceito, muitas vezes, diferentes, se fazendo necessário a analise de todos eles para que no final, busque-se uma aproximação com o conceito dito como perfeito para a empresa.

A justificativa que nos levou a escolher o tema foi à necessidade de estudos do conceito da empresa, seja ele na área econômica, jurídica ou social, posto que, o problema do tema é que não existe conceituação positivada do que seria empresa, por este motivo, estudaremos diversas teorias, tendo em vista ser esta à única fonte de se alcançar a aproximação do conceito de empresa.

Diante disso, nosso objetivo geral é de determinar, já alertando que sem muito aprofundamento, devido a densidade do tema, o conceito de empresa, se esta deveria aplicar o conceito econômico, jurídico ou social, bem como, como objetivo específico, será o de analise conceitual econômico, jurídico e social do tema, analisando os pressupostos fundamentadores dos diversos autores, tanto da literatura nacional como estrangeira.

Para o alcance da pesquisa esperada, usaremos a metodologia de pesquisa bibliográfica, tanto da época do Código Comercial, quanto atualmente, com o Código Civil brasileiro.

\section{FASES DO DIREITO COMERCIAL}

Antes de entrarmos no estudo dos conceitos da empresa, se faz necessário entender de onde sugiram o comércio e o direito comercial, por este motivo, abordaremos uma simples evolução histórica do surgimento do comércio e consequentemente do direito comercial, de atos do comércio e da teoria da empresa.

Na primeira fase, foram criadas pelos burgueses as corporações de ofício, de comerciantes e mercadores, buscando regular, através de estatutos, as diretrizes destes comerciantes. Nesta fase, tem-se um conceito subjetivo de comerciante, posto que, só era considerado comerciante aquele que participava da corporação de ofício.

Na segunda fase, com a criação do Código Civil Francês em 1804 e o Código Comercial Francês em 1808, houve o desaparecimento dos poderes das corporações de ofício, sendo os comerciantes tratados de forma objetiva, com a criação da Teoria dos Atos de Comércio e a criação do direito civil e do direito comercial.

Existiam dois sistemas de atos de comércio, o descritivo e o enumerativo. O descritivo, adotado por Portugal (Código Comercial Português de 1833) e também pela Espanha (Código Comercial Espanhol de 1885) onde é descrito características do que seriam atos de comércio. Já o enumerativo, adotado pelo Brasil (Código Comercial brasileiro de 1850) enumerava um rol do que seria mercancia.

Na terceira fase, com a criação do Código Comercial Italiano em 1942, se tem a criação da Teoria da Empresa, onde se buscou abranger mais o conceito de comércio e alocou também outros tipos de empresas como 
a de prestação de serviços, que não eram atos de comércio descrito no rol, posto não se tratar de comerciantes. Assim, volta-se ao critério subjetivo, porém, denominado, subjetivo moderno, passando a ser concentrado no sujeito, o empresário.

Como visto, foram necessárias muitas evoluções e muitos séculos para a formação de comércio e do direito comercial, onde eram adotados os atos de comércio, para então chegar ao direito empresarial, adotando a teoria empresarial, que hoje ainda é utilizada, inclusive no Brasil. Passaremos agora a demonstrar as teorias dos atos de comércio, para melhor entendimento.

\section{TEORIA DOS ATOS DE COMÉRCIO}

Para Alfredo Rocco atos de comércio tem um conceito unitário, não sendo necessário um rol descritivo ou enumerativo, onde o mesmo defende que existe um "conceito comum, que se acha inerente em todas as quatro categorias de atos intrinsicamente comerciais: na compra para revenda e ulterior revenda, nas operações bancárias, nas empresas e nas instituições de seguros." (ROCCO, 2003).

Além disso, Alfredo Rocco defende que não é necessário o lucro para se ter um ato de comércio, sendo necessário apenas que haja a intermediação da circulação, onde descreve que para "o ponto de vista do nosso direito positivo a intenção do lucro não se exige." (ROCCO, 2003).

Alfredo Rocco argumenta ainda que, mesmo que se trate de atividade organizada de forma sistemática, quando o empresário não se valesse do trabalho de outrem, não haveria ali ato de comércio, dizendo que "o conceito de empresa, segundo a lei comercial", parte da ideia de que ela é "um ato de interposição entre os trabalhadores e o público", valendo-se o empresário do trabalho de outrem, o que "não ocorrendo, isto é, se o empresário não vier a contar com a cooperação de terceiros trabalhadores", ainda que haja "organização sistemática" dos meios de produção e de intermediação na troca, "não haverá ato de comércio", nem, em consequência, empresa, juridicamente falando. Compartilhando assim, da teoria poliédrica de Alberto Asquini, que se trata que conceitua empresa por quatro aspectos: subjetivo, objetivo, funcional e corporativo, que será explicado adiante. (ROCCO, 2003)

E por fim, conclui Alfredo Rocco que "é ato de comércio, todo ato que realiza ou facilita uma interposição na troca." (ROCCO, 2003).

A objetividade dos atos de comercio para CESARE VIVANTE se da "porquanto o legislador os considerou como commerciaes attendendo à sua natureza, e não à pessoa que os pratica”. (VIVANTE, 1918)

Cesare Vivante conclui dizendo que os atos de comercio podem se resumir não em quatro grupos, como Alfredo Rocco, mas sim, em cinco grupos, sendo que "A fim de os ter mais facilmente presentes, estes actos podem 
reunir-se em cinco grupos: I. Negócios sobre mercadorias; II. Negócios sobre crédito; III. Negócios sobre trabalho; IV. Negócios sobre riscos; V. Negócios marítimos.”. (VIVANTE, 1918)

Já para Otávio Mendes, o ato de comércio se caracteriza na compra do produto, ou seja, quando o comprador é um não comerciante, não existe ali ato de comércio, só se for comprado de um comércio por outro comerciante ou de um comerciante por um não comerciante.

A razão é que o contrato de compra e venda é um só, cuja natureza comercial ou civil é determinada pela dívida do mesmo resultante. O elemento predominante do contrato, portanto, é a compra, com as responsabilidades à mesma inerentes. A venda, por si só, não influi sobre a natureza jurídica. (MENDES, Otávio. 1930)

Discordando desta teoria de Otávio Mendes, temos o saudoso José Xavier Carvalho De Mendonça, quando descreve, fundamentando no artigo 11 do Regulamento 737 de 1850, que é impossível atribuirmos de forma geral que se um comerciante comprar seria ato de comércio, sendo que poderia o mesmo comprar para consumo próprio e não revenda, não sendo assim, um ato de comércio, assim, descreve que:

Artigo 11 do Regulamento 737 de 1850: Não basta, para determinar a competência da
jurisdição comercial, que ambas as partes ou algumas delas seja comerciante, mas é essencial
que a divida seja também comercial; outrossim, não basta que a dívida seja também
comercial, mas é essencial que ambas ou uma das partes seja comerciante[...]
(MENDONÇA, 1956)

Assim, os atos de comércio, sofreram muitas discussões, existindo várias teorias sobre o que seriam e também como deveriam ser interpretados e aplicados, não tendo este artigo como abranger todas as teorias e todos os estudos sobre o tema, porém, demonstrado em algumas doutrinas que se divergem e talvez, se anulam.

Como visto, comércio conseguimos demonstrar neste capítulo algumas opiniões, sobre os atos de comércio, sendo que, estes, mesmo sendo objetivos, criaram muitas teorias da forma de aplicação e de interpretação, passando agora ao estudo da aplicação no Brasil dos atos de comércio e da teoria da empresa.

\section{DIREITO COMERCIAL NO BRASIL}

No Brasil, começou-se a exercer o chamado comércio positivo em 1808, com a criação da Carta dos Portos, e logo em seguida em 1832 foi criada a comissão para elaborar o Código Comercial Brasileiro, aprovado em 1834 pelo Congresso e transformado na Lei 556 de 1850.

O Código Comercial Brasileiro adotou a teoria francesa de atos de 1804, porém, não enumerou quais as atividades seriam considerados atos de comércio, por isso, no mesmo ano, foi editado o Regulamento 737 onde descreveu no seu artigo 19 quais seriam estes atos de comércio, onde como já descrito, no Brasil utilizava-se do sistema enumerativo, enumerando quais seriam os atos de comércio de forma objetiva.

Para Carvalho De Mendonça, existiam três formas de atos de comércio, a por natureza, a por conexão e a por força de lei. (MENDONÇA, 1956) 
Os atos de comércio por natureza são os atos inerentes ao exercício normal da mercancia, onde pelo menos umas das partes eram comerciantes e com finalidade de comércio.

Os atos de comércio por conexão são atos a princípio com perfil civil, porém, quando praticados com intuito de comércio, assumem o caráter de atos de comércio. Exemplo: compra de uma máquina registradora, de balcões.

Por fim, os atos de comércio por força de lei, são independentes de qualquer critério científico, estão definidos na lei por atos de comércio. Exemplo: atividades inerentes às sociedades anônimas.

Em 1875, o Regulamento 737 de 1850 foi extinto, porém, continuou-se utilizando do mesmo até meados de 1942, quando foi criado o Código Civil Italiano, criando a então Teoria da Empresa que começou a chegar ao Brasil por meio de doutrinas e jurisprudências. Podemos citar como exemplo, o Código de Defesa do Consumidor, de 1990 que trouxe o fornecedor um conceito muito mais próximo da teoria das empresas do que de comerciante, abrangendo diversas áreas, não só o comércio.

Em 2002, foi instituído o Novo Código Civil, que acaba com a teoria Francesa dos atos de comércio e adota de vez a teoria Italiana da empresa. Com a criação deste código foi derrogado o Código Comercial de 1850 - pelo menos a primeira parte do mesmo, posto que, a parte do comércio marítimo ainda continua - unificando o direito privado.

Assim, como visto, o direito comercial veio para o Brasil influenciado pela teoria francesa de atos de comércio, sendo criada legislação que descrevem esses atos, porém, após a criação da teoria da empresa, começouse a adotar no Brasil por meio de decisões jurisprudenciais e por meio de doutrinadores, sendo formalizado em 2002 pelo novo Código Civil, que unificou o direito privado - civil e comercial. Assim, verificaremos agora o que seria comércio e sua autonomia no direito privado.

\section{AUTONOMIA DO DIREITO COMERCIAL}

O direito comercial se consagrou no meio jurídico, pois foi o comércio a atividade propulsora deste ramo do direito. Porém, a expressão Direito Empresarial é juridicamente mais adequada, posto que inclua outras atividades, além do comércio.

Para se descrever a autonomia do Direito Comercial, podemos citar duas formas, o legislativo ou forma e a substancial ou jurídica.

Na primeira, podemos citar a própria Constituição Federal de 1988 quando em seu artigo 22, inciso I, descreve que, "Art. 22, I, da Constituição Federal - Competência da União para legislar sobre direito civil e comercial". 
Ou seja, a Constituição Federal, atribuiu competências para a União legislar sobre o direito civil e o direito comercial, e não sobre o direito privado unificado. Assim, mesmo que unificado, existem dois perfis de direito privado, o comum e o especial, conforme o previsto.

Já a autonomia substancial ou jurídica, podemos dizer que existem características distintas entre os ramos, sendo que um, tutela a proteção comum ou geral e o outro a proteção específica das empresas.

Cesare Vivante, em opinião à autonomia do instituto sustentou que:

[...] na vida moderna há certa uniformidade das obrigações, o que não justificaria dois tratamentos, um pelo direito civil e outro pelo direito comercial. As normas comerciais foram criadas pelos comerciantes para defesa de seus próprios interesses. A manutenção da autonomia só se justificaria se o interesse maior da comunidade fosse à prosperidade dos comerciantes. (VIVANTE, 1918).

$\mathrm{Na}$ época era discutida a necessidade de um direito especial ou, se seria possível e melhor a unificação dos códigos. Alfredo Rocco descreve que:

O contínuo e crescente alargamento da esfera de ação do direito comercial induziu alguns escritores autorizados a negar a necessidade e oportunidade de um direito especial ao comércio, e a sustentar, ao contrário, a necessidade de fundir o direito comercial com o direito civil das obrigações em um código único das obrigações. (ROCCO, 2003).

Descreve ainda Alfredo Rocco que iniciado em 1888 por Cesare Vivante, a ideia de unificação foi ganhando aderência com o decorrer do tempo, e ainda, após Vivante criar um "brilhante e genial ensaio prolusione - foi conquistando dia a dia maior favor. A ele aderiram: Bolafio, Sraffa, Bruschettini." Completa Rocco que “Ao contrário combateram-no Manara, Vidari e Sacerdoti. (ROCCO, 2003).

Alfredo Rocco descreve que o fundamento para a corrente que aderiu à unificação era que:

O desenvolvimento histórico do direito comercial e o estudo das suas condições atuais provam que, de fato, hoje o direito comercial já não regula somente o fenômeno social do comércio, antes se transformou em direito comum, o qual regula comerciantes e não comerciantes, atos de comercio e atos que de comércio só tem o nome, mas que efetivamente são atos da vida civil. (ROCCO, 2003)

Após sofrer diversas críticas de Alfredo Rocco, que era a contra a unificação do Código Comercial, e defendia a autonomia do instituto, Cesare Vivante modificou em 1919 sua opinião e se retratou descrevendo que, o método do direito comercial é indutivo, prevalecendo o estudo empírico de fenômenos técnicos. Reconhece a natureza cosmopolita do direito comercial, afirmando a criação de um único mercado mundial.

Alfredo Rocco assevera que a preponderância de normas que defendam os interesses dos comerciantes não tem qualquer influência na autonomia do direito comercial. A influência dos comerciais vem do seu poder sobre a opinião pública e dos poderes do Estado. Que o problema dos limites entre os ramos do direito é uma constante. Que a atividade comercial reclama do direito uma maior simplicidade de formas e uma mais eficaz tutela do crédito. (ROCCO, 2003)

O Direito Comercial é um ramo autônomo da ciência do direito, posto que, tem seus próprios princípios, seus métodos e também objetivos próprios. 
Sendo que, os princípios são a onerosidade, a facilidade de formação e extinção de obrigações, a pontualidade, entendida como a proteção do crédito, e, por fim, facilidade de transmissão das obrigações, muito vista nos títulos de crédito.

Seus métodos é o indutivo, sendo que no direito comum civil utiliza-se do método dedutivo.

E por fim, seus objetivos próprios são a empresa.

\section{Características do direito empresarial}

O Direito Empresarial tem suas próprias características, sendo a informalidade ou simplicidade das formas, a onerosidade, o cosmopolitismo ou internacionalidade, o individualismo e a elasticidade.

A informalidade ou simplicidade das formas, sendo que o Direito Comercial tem que ser mais célere do que o Direito Civil, tendo que ser menos formalista.

A onerosidade é no sentido de que, em tese, todo ato mercantil é oneroso.

O cosmopolitismo ou internacionalidade é uma característica do Direito Privado, onde este tem traços internacionais, o que outros ramos do direito começaram a adquirir somente agora com a globalização.

O individualismo, posto que o lucro esteja ligado ao interesse individual, contudo sofre intervenção estatal.

E por fim, a elasticidade, onde descreve que o Direito Comercial é muito mais renovador e dinâmico do que os demais ramos do direito.

\section{CONCEITO ECONÔMICO DA EMPRESA}

Como nos outros códigos estrangeiros, no Brasil o legislador não se ocupou de definir de forma positiva o conceito de empresa, somente do empresário e descreveu as sociedades empresárias, por este motivo, se faz necessário à verificação por meio de entendimentos doutrinários.

A noção de empresa, no Brasil, advém do conceito da economia sobre empresa, ligada à ideia central de organização dos fatores, com objetivo de realização de uma atividade econômica.

\section{Teoria neoclássica tradicional}

A visão microeconômica tradicional neoclássica da empresa surge em 1883 quando Carla Izolda Fiuza Costa Marshall descreveu a empresa como sendo "[...] um mero agente econômico de um determinado mercado, de caráter racional e maximizado." Este agente racional então, visa maximizar os seus lucros. (MARSHALL, 1983) 
Leon Walras reafirmou o modelo de Marshall e acrescentou algumas teorias, como a teoria dos preços, onde os preços deveriam ser predefinidos, como em um leilão para que haja equilíbrio no mercado "os preços que permitem igualar oferta e demanda são previamente determinados e não existe incerteza em relação ao valor futuro das diferentes variáveis." (WALRAS, 1883).

Já em 1920, Sraffa, Robinson E Chamberlin, discordando da teoria dos preços (concorrência perfeita), de Walras, pois, esta não era compatível com a realidade, posto que agentes econômicos não fossem influenciados apenas pelos preços, onde "o preço de um produto não é o único fator determinante da decisão de um consumidor, outros atributos como a qualidade e o prestígio de uma marca também expressão as preferências dos indivíduos." (SRAFFA, ROBINSON e CHAMBERLIN 2005).

Motivaram assim, um novo debate para redefinir o conceito e natureza de empresa, quando começou a segunda fase, onde a empresa era um instituto e também tinha que ter uma visão gerêncialista.

Após a acepção econômica é que se torna possível a conceituação jurídica da empresa, interpretando e algumas vezes até importando o conceito econômico de empresa.

\section{Visão institucional e gerêncialista da empresa}

A discussão da natureza da empresa continuou com Ronald Coase, passando da ideia de que, a teoria tradicional de Marshall poderia ser aplicada, porém, as decisões de preços deveriam ser tomadas pelo empresáriocoordenador, exercendo a função de leiloeiro - descrito por Walras - no mercado, buscando na verdade não o preço em si, mas a redução dos custos, abrindo um debate da empresa como instituição, descrevendo que:

À presente discussão está na suposição de que uma empresa deve ser interpretada não como um mero agente maximizador do mercado, mas como uma instituição que tem suas relações reguladas contratualmente, de tal modo que os custos de transação envolvidos sejam minimizados. (COASE, 1937).

Porém, estes pensamentos de empresa como instituição, são criticados pela corrente gerêncialista, que tiveram como precursores Berle \& Means, que após estudos nos Estados Unidos determinou que a nova forma de gerenciar a empresa era chamada de Moderna Sociedade Anônima. (BERLE \& MEANS, 1984)

Tendo o principal foco na separação entre gestão e propriedade das empresas. Descreve os autores que "enquanto a revolução industrial separou o trabalho do controle de seus instrumentos de produção, uma nova revolução, a das sociedades anônimas, separou e vem separando a propriedade do controle sobre os investimentos" (BERLE \& MEANS, 1984).

Assim, foram enfatizadas por estes e outros autores, nesta fase, novos critérios da empresa, que criticam a teoria tradicional, que era baseada nos preços, e enfatiza a concorrência baseada na qualidade e nos esforços de venda. 
Buscou-se então a qualificação de pessoas que gerenciariam as empresas, para que estas sobrevivessem às mudanças do mercado, aos gostos dos consumidores, dentre outras coisas, o que nos levou à teoria gerêncialista da empresa, surgindo então a tecnoestrutura da empresa.

\section{A tecnoestrutura da empresa}

Nesta fase, a crítica também é na teoria tradicional da empresa, desenvolvida por Marshall, dizendo John Kenneth Galbraith que esta teoria só se aplicava para "[...] propriedade individual, e que demandam baixo ou nenhum volume de capital, de tecnologia e dos complexos recursos organizacionais típicos das empresas modernas." (GALBRAITH, 1984).

John Kenneth Galbraith argumenta que passou a existir à Sociedade Industrial Moderna, onde o mercado começaria a ficar somente com grandes concentrações de algumas grandes empresas, ajudando no controle de preços e sendo possível a instalação de tecnologias mais apuradas para melhorar as empresas, o que não é possível em muitas empresas pequenas e espalhadas. (GALBRAITH, 1984)

Para o autor, o empresário tradicional é substituído por um grupo de pessoas, sendo que:

[...] na indústria moderna, grande número de decisões, e de todas as que sejam importantes, recorre a informações que são possuídas por mais de um homem. Tipicamente, recorre-se a conhecimento especializado científico e técnico, a informações acumuladas ou à experiência e ao senso artístico e intuitivo de muitas pessoas [...]. Por conseguinte, a decisão na empresa moderna é produto não de indivíduos, porém de grupos. (GALBRAITH, 1984, p. 58-60).

Entende o autor que o objetivo das empresas é o de alcançar um processo interno de crescimento e acumulação de capital, onde para isso, deve adotar estratégias para os consumidores e ter uma estrutura organizacional condizente com o mercado.

Assim, tem-se a evolução do conceito econômico de empresa, descrita por economistas de épocas diferentes, argumentando suas teorias e buscando aperfeiçoá-las.

Começasse por empresa com intuito de padronizar os preços, buscando um mercado perfeito, onde a procura e a demanda se exauriam, porém, com as críticas foi visto que este mercado é impossível de atingir, sendo necessário ter a empresa o controle do preço, de forma interna, se ajustando, diminuindo os custos, ou seja, gerenciando de forma correta.

Em seguida, percebermos que foi criada uma nova sistemática, onde as empresas deveriam na verdade ser gerenciadas de uma forma organizada, por mais de uma pessoa, juntando estruturas para diversificar produtos e ajustar-se às modificações do mercado. E entendemos que este é o praticado hoje pelas empresas, com baixa dos custos em busca do aumento de capital, organização sistemática, diversificação de produtos para atendimento dos consumidores e gerenciamento por mais de um empresário. 
Desta forma, após verificarmos os conceitos de empresa para a economia e estudarmos como as empresas estão se estruturando hoje, passaremos a estudar os conceitos jurídicos de empresa.

\section{CONCEITO JURÍDICO DA EMPRESA}

Sabemos que a empresa é organizada com a finalidade de atingir os consumidores, como descrito no conceito econômico. Muitos autores importam esse conceito e adotam como jurídico. Porém, alguns autores discordam desta forma de atribuir o conceito de empresa no ramo jurídico, preferindo a forma de tradução dos conceitos econômicos para os termos jurídicos.

Para Fábio Ulhoa Coelho, a empresa é uma atividade "[...] organizada com a finalidade de fazer circular ou produzir bens ou serviços". (COELHO, 2001)

Gladston Mamede, ao conceituar juridicamente a empresa descreve que:

É a organização de meios materiais e imateriais, incluindo pessoas e procedimentos, para a consecução de determinado objetivo (o objetivo social), com a finalidade genética de produzir vantagens econômicas que sejam aproveitáveis por seus titulares, ou seja, lucro que remunere aqueles que investiram na formação do seu capital empresarial. (MAMEDE, 2013).

Marlon Tomazette, também conceituou empresa, descrevendo que "empresa é atividade econômica organizada para a produção ou circulação de bens e serviços para o mercado”. (TOMAZETTE, 2007)

José Xavier Carvalho de Mendonça, ao conceituar empresa, segue os preceitos de seu contemporâneo Vivante, quando diz que a empresa é:

A organização técnico-econômica que se propõe a produzir mediante a combinação dos diversos elementos, natureza, trabalho e capital, bens ou serviços destinados à troca (venda), com esperança de realizar lucros, correndo os riscos por conta do empresário, isto é, daquele que reúne, coordena e dirige esses elementos sob a sua responsabilidade. (MENDONÇA, 2000).

Pode-se perceber que existe um padrão nos conceitos, onde a empresa pratica atividade organizada, com a finalidade intermediária de produção ou circulação de bens e serviços.

Porém, sabemos que não existe um conceito positivado, ou seja, nenhuma legislação descreveu o conceito de empresa, nem o Código Civil Italiano de 1942, nem o Código Civil Brasileiro de 2002, ambos se esquivaram em conceituar a empresa, descrevendo apenas sobre o empresário.

Assim, se torna extremamente desgastante e descritivo a explicação do conceito de empresa, sendo necessária - como foi feito - a transcrição de diversas teorias, se fazendo necessária a edição de uma norma transcrevendo o conceito de empresa para o meio jurídico, seja de forma a importar a do conceito econômico, seja em traduzir o conceito para o jurídico. 
Estudado assim o conceito de empresa, mesmo sem exaurir as fontes, passaremos a verificar o conceito social da empresa, onde se tem alguns debates doutrinários, tendo em vista que a função social da empresa é um conceito aberto, sendo interpretado da forma que melhor convier ao intérprete.

Desta forma, podemos dizer que um conceito que seria pelo menos consensual da empresa seria organizada com finalidade de produzir ou circular bens e serviços para o mercado, sob a responsabilidade do empresário, com intuito de lucro.

\section{A teoria da empresa}

Instituída no Brasil pelo Código Civil de 2002, sendo tratada no Livro II da Parte Especial (artigo 966 a 1.195), com o nome de Direito Empresarial.

Descreve Waldírio Bulgarelli que "[...] nos dias que correm, transmudou-se (o direito comercial) de mero regulador dos comerciantes e dos atos de comércio, passando a atender à atividade, sob a forma de empresa, que é o atual fulcro do direito comercial [...]”. (BULGARELLI, 1995)

Passou a tratar então, a empresa como forma e não como ato praticado pelo empresário, o que levaria a teoria dos atos de comércio, onde quem praticava era descrito como comerciante, passando na nova teoria, o conceito tendo um significado mais abrangente.

\section{Teoria dos perfis da empresa}

Existem duas teorias sobre o perfil da empresa, o qual conceituaria a empresa que tivessem estes perfis, na primeira corrente, Alberto Asquini cria a Teoria Poliédrica, onde conceitua que "a empresa deve ser vista a partir de ângulos distintos, combinados entre si e não tomados isoladamente." E ainda descreve que, "diversos perfis jurídicos sob os quais o código considera o fenômeno econômico da empresa". Para Asquini a empresa deveria ter quatro perfis, sendo o subjetivo, o objetivo o funcional e o corporativo. (ASQUINI, 1996)

1. O subjetivo é o empresário, que pratica a atividade empresarial;

2. O objetivo seriam os instrumentos para esta atividade empresarial, como por exemplo, o maquinário, os bens;

3. O funcional é a própria atividade empresarial e;

4. O corporativo é o empresário e os colaboradores.

Para a segunda corrente, a teoria dos perfis da empresa deveria ter parado no perfil funcional, Waldírio Bulgarelli, como outros doutrinadores entendem que o perfil corporativo não entraria para o perfil da empresa, posto que, poderia existir empresa sem que esta tenha o perfil corporativo, ou seja, não seria necessário o colaborador, adotar então a Teoria Triédrica, que descreve que empresa seria a "atividade econômica organizada 
de produção e circulação de bens e serviços para o mercado, exercida pelo empresário, em caráter profissional, através de um complexo de bens.". (BULGARELLI, 1995)

Bulgarelli utilizou-se de diversos argumentos para justificar sua teoria Triédrica, dentre eles:

Essa ideia de organização de pessoas, como corpo social, estruturada com base numa hierarquia em relação a uma ideia diretriz, capaz de manter sua integralidade apesar das mutações em seus elementos, está contida também em Hauriou e seu seguidores. Mas, primeiro, é incontestável que se trata de visão sociológica: e segundo, que dá relevo aos aspectos da organização estável que sobrevive e permanece independente das vicissitudes de seus membros, em razão de uma ideia a realizar. Nesse sentido é que é vista comumente, atribuindo-se essa designação às escolas, às sociedades, às fundações e ao próprio Estado. Mas, certamente, não tem correspondência às categorias jurídicas; referindo-se à instituição como um conjunto de regras estáveis, ou uma organização de pessoas e de bens, terá sua importância para influenciar o jurista ou o legislador, em termos axiológicos talvez, mas, sem dúvida, não permite sua qualificação entre as categorias jurídicas fundamentais. (BULGARELLI, 1995).

Assim, temos a discussão de duas teorias da empresa, uma que engloba o trabalho, ou seja, os colaboradores e outra que defendo apenas o empresário, o estabelecimento e a empresa.

\section{CONCEITO SOCIAL DA EMPRESA}

Para que seja possível falarmos sobre o conceito social da empresa, se faz necessário abordarmos a evolução histórica para se formar a Constituição Federal de 1988, onde prevê em dois capítulos diferentes a "Da Ordem Econômica e Financeira" e "Da Ordem Social".

A evolução se deu com a Revolução Francesa que aconteceu nos anos de 1789 - 1799. A primeira grande vitória da revolução foi quando em 1789 foi aprovado a Declaração dos Direitos do Homem e do Cidadão, onde foram criados então os primeiros direitos fundamentais, chamados pela doutrina de direitos fundamentais de primeira dimensão, sendo eles: Direito à vida; à liberdade; à propriedade; à igualdade perante a lei; ao devido processo legal.

A segunda fase da evolução se deu com a Revolução Industrial, onde a burguesia buscava se firmar no cenário utilizando o trabalho do homem pelo homem, começa-se então a chamada, classe proletária e a exigência desacerbada aos trabalhadores, que laboravam diariamente, sem nenhum direito. Nesta época, os proletariados, apoiados por filósofos-políticos da época, como Karl Marx, que criaram ideais para o levante dos proletários, exigiram do Estado uma intervenção protecionista, sendo criados então, na época, os direitos fundamentais, chamados de segunda dimensão, tais direitos não substituíram os de primeira dimensão, apenas complementaram aqueles.

São direitos fundamentais de segunda dimensão o: Direito à assistência social; ordem econômica; saúde; educação; igualdade material e não meramente formal; ao trabalho. 
Tais direitos foram firmados na Constituição Mexicana (1917) e Constituição de Weimar (1919), onde constaram os primeiros direitos fundamentais da época, começando então uma nova era constitucional.

No Brasil, a primeira Constituição a prever a ordem financeira e social foi a de 1934, que foi dividia em 1988, passando a ser "Da Ordem Econômica e Financeira" e "Da Ordem Social", garantindo assim a todos, os direitos fundamentais de primeira e segunda dimensão, onde se buscaria pelo trabalho e a livre iniciativa o bemestar social de todos com o objetivo maior de se garantir a dignidade da pessoa humana, uma forma de justiça social.

Nesta Constituição Federal, de 1988, os conceitos econômicos e sociais - que garantem os direitos fundamentais por meio do Estado, que busca contribuição de todos - estão previstos nos artigo 170 e 183.

José Afonso da Silva descreve que a empresa, tem um fim e deve cumprir o mesmo, quando diz que a Constituição "não estava simplesmente preordenando fundamentos às limitações, obrigações e ônus relativamente à propriedade privada, princípio também da ordem econômica e, sujeita, só por si ao cumprimento daquele fim." (SILVA, 2007).

Acrescentando ao conceito social da empresa, COMPARATO, descreve que:

A função social da propriedade não se confunde com as restrições legais ao uso e gozo dos bens próprios; em se tratando de bens de produção, o poder-dever do proprietário de dar à coisa uma destinação compatível com o interesse da coletividade transmuda-se, quando tais bens são incorporados a uma exploração empresarial, em poder-dever do titular do controle de dirigir a empresa para a realização dos interesses coletivos. (COMPARATO, 1971).

Assim, a empresa tem sua função social, prevista na Constituição Federal, e ainda em leis, sendo dentre estas a ambiental, trabalhista, que existem penalidades por descumprimento da chamada "função social".

\section{Falha no fundamento social da empresa}

Alguns autores descrevem que a empresa não tem função social, sendo que sua finalidade é unicamente a geração de riqueza, sendo esta a sua função social, nada mais. Dentre estes autores, podemos citar John Mayer Keynes, quando descrevem que, "a única função social da empresa consiste em utilizar seus recursos para maximizar o lucro em benefício dos acionistas [...]”. (KEYNES, 1973)

Margaret Blair, afirmou em 1998 que o conceito social da empresa é falho, e que as empresas sociais como descritos nos séculos 60 e 70, não prosperou tendo em vista que não ofereceu alternativas para à empresa clássica, dizendo que "a própria concepção de empresa social carece de sólido fundamento teórico, ao contrário da noção clássica da empresa como unidade fundamental da economia de mercado”. (BLAIR, 1998)

Além disso, complementou que "a noção de empresa social não é, ademais, suficiente para orientar o investimento das empresas nem para ajudá-las a escolher entre formas alternativas de atividade social.". (BLAIR, 1998) 
Assim, Margareth Blair chega à conclusão que os conceitos existentes hoje de função social da empresa, não têm uma fundamentação teórica definida, onde as empresas possam verificar o que fazer e como fazer, sendo um conceito amplo, intangível.

Sabe-se que as empresas antes da Constituição Federal de 1988 não tinham a preocupação com as suas funções sociais, preocupando apenas com o objetivo lucro, porém, após a Constituição, as empresas tiveram que pensar não só na geração de riqueza, mas também, no seu objetivo social perante a sociedade.

\section{CONCLUSÃO}

Apesar de vários estudos, conforme exposto, os doutrinadores e legisladores não chegaram a uma definição positivada de conceito de empresa, tendo apenas teorias isoladas, onde algumas são parecidas, outras se anulam e algumas se completam.

Muitos estudos são a favor da unificação do direito privado, alguns são contra a unificação, preferindo a aplicação em direito civil e em direito comercial, como Alfredo Rocco e Cesare Vivante (que mudou a sua concepção em 1919), porém, como se percebeu a autonomia do direito comercial é prevista no direito positivo e também em características únicas, bem como princípios e métodos. Porém, o que penso sobre o assunto, é que o Direito Comercial deveria ter seu código próprio, unificando diversas leis esparsas que hoje existe, como a de S/A, a de Cheque, e porque não, unificar também o direito do consumidor juntamente com o Código Comercial, onde trataria das obrigações da empresa perante o consumidor e os direitos do consumidor perante a empresa. O que facilitaria o estudo, posto que, teríamos uma norma geral para a empresa no geral, e ainda, aplicações especiais para cada tipo de livro.

Os conceitos jurídicos e econômicos se confundem hoje na doutrina, posto que, muitos, inclusive no Brasil, defendem a importação do conceito econômico para o jurídico, sendo outra parte dos autores estudados, defendem que o conceito jurídico deve apenas traduzir o conceito econômico em termos jurídicos. Somos adeptos à corrente que defende a tradução do conceito econômico para o jurídico, posto que, não se pode concluir que as mesmas normas e entendimentos aplicados na economia, poderiam ser aplicados no direito, como por exemplo, no direito tributário, que seria impossível utilizar os conceitos econômicos, v.g. no caso de leasing, onde a empresa não compra o produto, apenas utilizasse do meio de locação com opção de compra, para a contabilidade e o conceito econômico, tem-se que é patrimônio da empresa, já para o jurídico/tributário, não será patrimônio da empresa, e esta não terá praticado o fato gerador da compra, posto que, trata-se de locação, assim, entendemos que deve ser traduzido o conceito econômico para o jurídico, chegando-se na conclusão do que seria empresa no meio jurídico. 
Por fim, vimos que a função social da empresa não está devidamente formatada, não há uma teoria formada para que a empresa possa verificar o que seria a função social, sendo um conceito muito subjetivo. Assim, entendemos que deve ser aplicada, pelo legislador, uma fundamentação teórica do que seria a função social da empresa, tornado possível o empresário conhecer do que fazer, onde fazer, como fazer e quando fazer, bem como, se torna possível aplicações de sanções quando não cumprir esta função social. Desta forma, se faz necessário um trabalho futuro sobre o assunto, posto que, trata-se de um tema polêmico e muito interessante.

Concluímos então que, no estudo do conceito de empresa, de forma estática e positiva, é quase que impossível, posto que o direito empresarial (comercial) é modificado com muita constância o que poderia influenciar de forma negativa ter um conceito único, como aconteceu com os atos de comércio que com o decorrer do tempo perdeu-se a validade, mesmo que guardado as devidas proporções de comparações, em que adota o critério objetivo e a teoria da empresa adota o critério subjetivo, ainda, moderno.

\title{
ECONOMIC THEORIES, LEGAL AND SOCIAL ENTERPRISE
}

\begin{abstract}
The development of the business company is a subject much discussed in doctrine and jurisprudence, considering that to reach its development it is necessary to move the concept of company. So our goal will not be to complete what would now, given that in our view would not like, having a single, static definition of what is now, however, we seek to demonstrate what are the theories written since the mid-century XVIII until now in the twenty-first century, where we tried to get - and that's what came closer - to what would be the concept of enterprise. After using up bibliographic methods several times, ie since the first studies on commercial law, up to today's business law, came to the result that the concept of undertaking may not be regarded as static, you should always be in change, sometimes using the concepts and justifications, social, economic and legal. In conclusion then, in closing remarks that both the economic concept, as the legal and social can be applied to conceptualize the company, depending on the timing and the expected result, there is no single concept for now.
\end{abstract}

Keywords: Commercial Law. Business Law. Company concept. Company theories. Commercial Actos.

\section{REFERÊNCIAS BIBLIOGRÁFICAS}

ASCARELLI, Tullio. Evolução e Papel do Direito Comercial. In Revista dos Tribunais. Vol. 725. Mar/1996. São Paulo: Revista dos Tribunais.

ASQUINI, Alberto. Perfis da empresa. Tradução de Fábio Konder Comparato. Revista de Direito Mercantil, Industrial, Econômico e Financeiro. São Paulo, v. 35, n. 104, p. 109-126, out/dez 1996. 
BLAIR, Margaret M. The coporation and its stakeholders: classic and contemporany readings. Toronto: University os Toronto Press, 1998. Whose interests should corporations serve? P.47, apud RAE - Revista de Administração de Empresas, out/dez 2001, São Paulo, v.41, n.4.

BULGARELLI, Waldírio. Tratado de Direito Empresarial, 2. Ed., São Paulo, Altas, 1995.

COASE, R.H. The nature of the firm. In: WILLIAMSON, O. E e WINTER, S.G. (Org.).The nature of the firm: origins, evolution, and development. Oxford: Oxford University Press, 1993. Apud Revista de Economia de Mackenzie, v.3, n.3, 2005.

COELHO, Fábio Ulhoa. Curso de Direito Comercial - Direito de Empresa. 11. ed. São Paulo: Saraiva, 2007. Curso de direito comercial. 5. Ed. rev., 2001. São Paulo: Ed. Saraiva, 2001. V. 1, 491.

GALBRAITH, J. K. O Novo Estado Industrial. São Paulo: Abril Cultural, 1984. Apud Revista de Economia de Mackenzie, v.3, n.3, 2005.

HAYEK, F. A. Studies in philosophy, politics and economics. London : Routledge \& Kegan Paul., 1967. p. 300. apud RAE - Revista de Administração de Empresas, out/dez 2001, São Paulo, v.41, n.4.

KEYNES, John Maynard. The end of laissez-faire. In: GOULD, James A., TRUITT, Willis H. Political ideologies. New York : Macmillan, 1973. p. 97. apud RAE - Revista de Administração de Empresas, out/dez 2001, São Paulo, v.41, n.4.

LAGARDE, Hamel Et. Traité de Droit Commercial, vI. P. 251 e 4819, nos 213/216, cit. Por SYLVIO MARCONDES, ob. Cit, p.31, no 16, cf. ainda HARIOU ET RENARD, apud WALDÍRIO BULGARELLI, A Teoria Jurídica da Empresa, São Paulo, Ed. RT, 1985.

LOBO, Jorge. Revista da EMERJ. v.5, n.17, 2002.

MAMEDE, Gladiston. Manual de Direito Empresarial. São Paulo: Atlas, 2013.

MARSHALL, A. Princípios de economia: tratado introdutório. São Paulo: Abril, 1983. Apud Revista de Economia de Mackenzie, v.3, n.3, 2005.

MENDES, Octavio. Fallencias e Concordatas. São Paulo: Saraiva \& C. - Editores, 1930.

MENDONÇA, José Xavier Carvalho. Tratado de Direito Comercial Brasileiro. 1.ed. atualizada por Ricardo Negrão. Campinas: Brookseller, 2000.

NEGRÃO, Ricardo. Manual de direito comercial. São Paulo: Ed. Saraiva, 1981.

ROBINSON, J. The economics of imperfect competition. London: Macmillan, 1933. Apud Revista de Economia de Mackenzie, v.3, n.3, 2005.

RIPERT, George. Traité Elémentaire de Droit Commercial. Paris, LSDJ, 1980, v.I, p.219, no 358, citado em LOBO, Jorge. Revista da EMERJ. v.5, n. 17, 2002.

ROCCO, Alfredo. Princípios de Direito Comercial. GAMA, Ricardo Rodrigues (trad.). Campinas: LZN, 2003. 
REQUIÃO, Rubens. Curso de Direito Comercial. 27. ed. São Paulo: Saraiva, 2007, p. 42, v. I.

SILVA, José Afonso da. Curso de direito constitucional positivo. 28. ed. São Paulo: Malheiros, 2007.v. 1.928

SRAFFA, Piero. The laws of returns under competitive conditions. Economic Journal, Dec. 1926. ApudRevista de Economia de Mackenzie, v.3, n.3, 2005.

TOMAZETTE, Marlon. A teoria da empresa: o novo Direito "Comercial". Jus Navigandi, Teresina, ano6, n. 56, abr. 2002.

VIVANTE, Cesare. Instituições de Direito Commercial. ALVES DE SÁ, J., 2ª ed. Lisboa, Livraria Clássica Editora, 1918.

WALRAS, M. E. Leoni. Compêndio dos elementos de economia política pura. São Paulo: Abril, 1983. Apud Revista de Economia de Mackenzie, v.3, n.3, 2005.

Trabalho enviado em 14 de agosto de 2015.

Aceito em 12 de outubro de 2015. 